\title{
ERRATUM
}

1) INDUSTRIAL HEALTH

(2009) Vol. 47, No. 2, Pages: 103-105.

\section{INDUSTRIAL HEALTH: From the Cradle to an International Journal}

Shunichi ARAKI

Editor-in-Chief, INDUSTRIAL HEALTH

President, National Institute of Occupational Safety and Health, Japan

Professor Emeritus, The University of Tokyo

Due to a technical error, the second paragraph of the right column on Page 103 was printed incorrectly. The paragraph should read as follow:

"For the last nine years, I have had the special privilege of promoting the scientific and administrative advancement of IH as well as first as the Director General of the NIIH in 2000, then as the President of the NIIH (2001-2006), re-organized as an independent semi-governmental institution under the new Ministry of Health, Labour and Welfare (MHLW) of Japan, and currently as the President of the newly founded National Institute of Occupational Safety and Health (JNIOSH, 2006-2009) ${ }^{33) . "}$

2) INDUSTRIAL HEALTH

(2009) Vol. 47, No. 3, Pages: 271-282.

\section{Factors Associated with Self-estimated Work Ability and Musculoskeletal Symptoms among Male and Female Workers in Cooled Food-processing Facilities}

Erja SORMUNEN ${ }^{1,2 *}$, Jouko REMES ${ }^{2}$, Juhani HASSI ${ }^{4}$, Tuomo PIENIMÄKI ${ }^{2}$ and Hannu RINTAMÄKI ${ }^{2,3}$

${ }^{1}$ Centre for Arctic Medicine, University of Oulu, P.O. Box 5000, FI-90014 Oulu, Finland

${ }^{2}$ Finnish Institute of Occupational Health, Aapistie 1, FI-90220 Oulu, Finland

${ }^{3}$ Institute of Biomedicine, University of Oulu, P.O. Box 5000, FI-90014 Oulu, Finland

${ }^{4}$ Institute of Health Science, University of Oulu, P.O. Box 5000, FI-90014 Oulu, Finland

The accepted date of the above paper was incorrect (Page 271). Its date should be "December 12, 2008". This correction has been completed on the electronic file of the present paper available at J-STAGE (http://www.jstage.jst.go.jp/browse/indhealth) and our website (http://www.jniosh.go.jp/ en/indu_hel/2009.html\#2009). 